\title{
Brief communication "What do we know about freaque waves in the ocean and lakes and how do we know it?" published in Nat. Hazards Earth Syst. Sci., 10, 2191-2196, 2010
}

\author{
P. C. Liu
}

NOAA/GLERL, Ann Arbor, Michigan, USA

I have received an email communication from L. Cavaleri (2011) regarding our recent Brief Communication in Nat. Hazards Earth Syst. Sci., 10, 2191-2196, doi:10.5194/nhess10-2191-2010, 2010 "What do we know about freaque waves in the ocean and lakes ..." with this comment:

"I must correct you on one point. At the bottom of the second page and beginning of the third one you quote the report of a young sailor about the "thundering through .... deafening roar" of the incoming freak (or freaque if you prefer) wave, and you say that this "is a new, never previously mentioned characterization of a freaque wave". Well, this is not true. (Emphasize added.)"

He went on to inform us his personal experience that was described on p. 84 of the book by Holthuijsen (2007) as shown in Fig. 1. And he further elaborated:

"The reason why I am mentioning this is that I was the person who experienced the freak wave on the oceanographic tower (photo attached as Fig. 2) and provided the description to Leo. Indeed it was a deafening, frightening roar. At the moment significant wave height was about $3.5 \mathrm{~m}$ with a mean sea level possibly one metre higher than in the picture. In any case the wave crests were well below the first floor. I was on the second one and the crest passed barely ten $\mathrm{cm}$ below my feet. I was very lucky. Otherwise most likely the tower now would have my name."

"Along that storm I had the best possible (for me) record of a serious storm and subsequent swell. Unluckily the instruments were not on at the moment of the freak wave. On the other hand this is the reason why I was not inside the tower, but out on the outgoing platform fixing the instruments for the subsequent run. From the scientific point of view it was a pity. For my personal experience it was the chance of a life time."

Now this is a very interesting and important experience from one who is not only an eyewitness that encountered a real life freaque wave but himself is also a scientist and wave aficionado. We sincerely appreciate Luigi's kindness in bring his experience to our attention and we stand being corrected and plead guilty for not carefully reading Holthuijsen (2007) book. Now we concur that our recognition of the sound characterization in freaque waves as provided by the young sailor was not "never previously mentioned", it was in fact "like a train coming" according to L. Cavaleri (personal email communication, 2011) before the "deafening roar". The existing of both of these two clear sound instances, however, certainly substantiates the fact that freaque waves do likely to be accompanying with unmistakable freaque sound effects and that can only confirm the need to further explore the sound aspects and may be developing detailed sonic recordings in connection with future freaque wave studies. Furthermore alerting the seafarers to be on guard and recognizing any probable unusual approaching sound for freaque waves would be more effective than any forecast scheme one can possibly amass at any events.

\section{References}

Holthuijsen, L. H.: Waves in Oceanic and Coastal Waters, Cambridge University Press, 404 pp., 2007. 
We were on the tower during the night in the middle of a storm with about $4 \mathrm{~m}$ significant wave height, I was fixing an instrument at about $7 \mathrm{~m}$ a.s.l., on a long horizontal extention of the platform. Suddenly I heard something like a train coming, and, looking in the dark, I could spot the whitish crest of a wave running against the tower at my height. There was nothing I could do. The crest passed barely below my feet before exploding against the structure. When I turned towards the tower, for a couple of seconds I could see only water. My colleques, who were watching from an upper deck, were soaked. I was dry.

Fig. 1. Cavaleri's encounter as given in p. 84 of Holthuijsen's book.

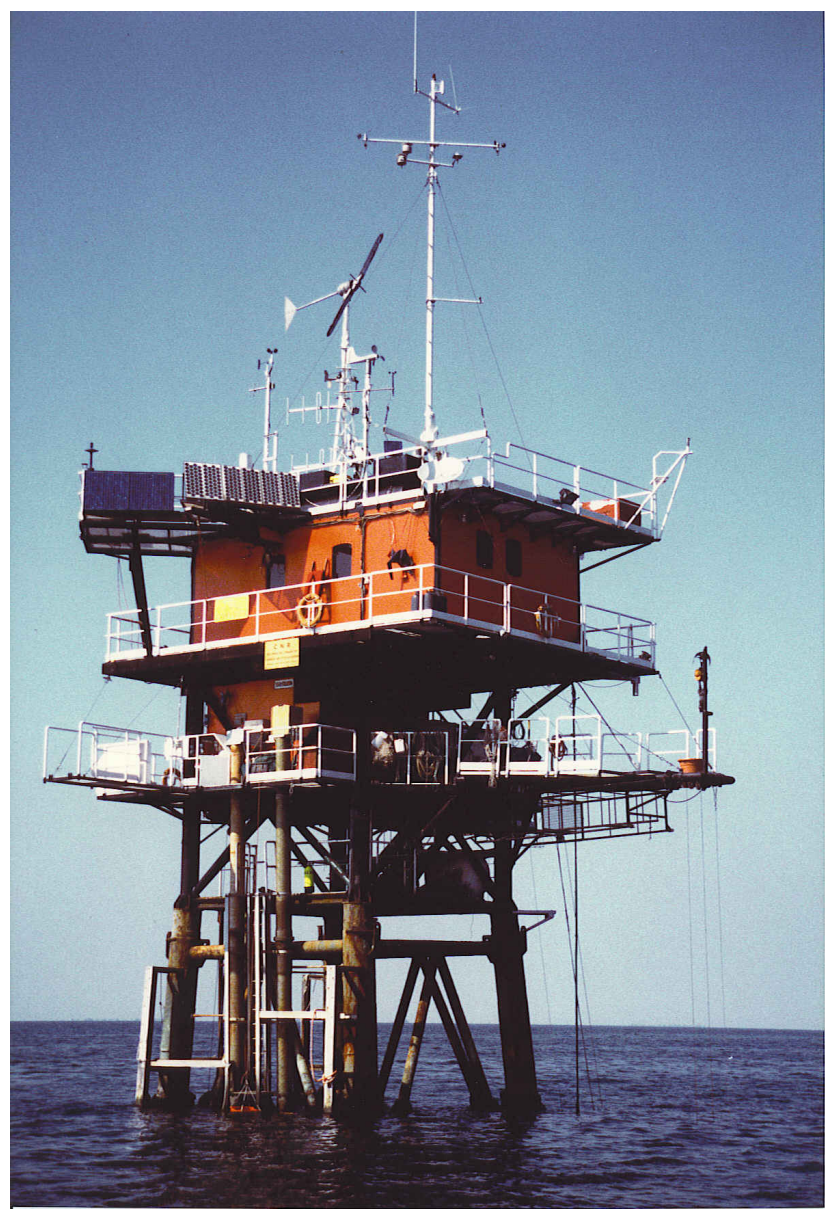

Fig. 2. The oceanographic Observation Tower in Adriatic Sea. 